\title{
The Mediating Role Of Popularity Rank On The Relationship Between Advertising And In-App Purchase Sales In Mobile Application Market
}

Yun Kyung Oh, Dongduk Women's University, South Korea Jihong Min, Myongji University, South Korea

\begin{abstract}
In the booming industry of mobile application, a new business model has arisen as a lucrative way of monetization, which is characterized by scaling up user base via free distribution and following partial monetization. As a result, popularity rank and in-app purchase revenue are increasingly emphasized. In this context, understanding the relation among popularity rank, in-app purchase sales, and advertising is essential to optimal marketing decisions. For this purpose, this research investigates how advertising influences in-app purchase sales via popularity rank. Through our empirical analysis of a mobile game data collected on a daily basis, we show advertising expenditure not only improves popularity rank, but also increases in-app purchase sales. In addition, we demonstrate that mobile advertising effect on in-app purchase sales is fully mediated by popularity rank.
\end{abstract}

Keywords: Mobile Application; Mobile Advertising; Popularity Rank; In-app Purchase

\section{INTRODUCTION}

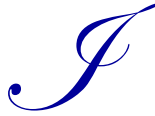

$\mathrm{n}$ recent years, mobile application (app) market size is increasing rapidly with the penetration of mobile devices such as smart phone and tablet personal computer. Mobile app industry is expected to grow from $\$ 53$ billion in 2012 to $\$ 143$ billion in 2016, including revenues from in-app purchases, in-app advertisements, and big data accumulation (B2C 2014). App stores of Apple and Google, two giant mobile operating system providers, offering more than 700,000 mobile apps each, paid approximately $\$ 5$ billion and $\$ 10$ billion respectively to mobile app developers in 2013, as developer portions of gross revenues from their mobile app stores (Businessweek 2014).

In the fast-growing mobile application market, a new business model which is called "Freemium", a portmanteau neologism combining "Free" and "Premium", has arisen as a lucrative way of monetization. The freemium model is characterized by scaling up user base via free distribution and following partial monetization. In the past, the "Premium" business model, purchase before using a product, has been widely used as the most popular business model in mobile app market. Currently, the freemium model is arising as a popular business model in general mobile app market, especially showing apparent growth in game category (Moreira et al. 2013). App Annie and IDC (2014) announced that freemium mobile app revenues in key countries ${ }^{1}$ increased by $211 \%$ from 2012 to 2013, while other mobile app revenues shrank in the same period. In some industries with decreasing distribution costs, monetization after scaling up user base via free distribution is becoming more persuasive. Kumar (2014) insists that the freemium business model has become the dominant business model among internet start-ups and mobile app developers, and is expected to grow more attractive in extensive areas ranging from media and education. Although the freemium business model has a clear benefit of enhancing user base with relatively low

${ }^{1}$ Brazil, Canada, France, Germany, India, Japan, Russia, South Korea, United Kingdom and United States. 
advertising expense by providing free features, marketers should carefully consider what to provide as a free feature, how to monetize users, and how to optimize conversion rate, and so on (Kumar 2014).

In the freemium business model, mobile app providers only monetize users whenever they are willing to pay for some features while using the app, and the revenue is based on a small percentage of total user base (Fields 2014). Taking an example of a freemium model in game industry, all the game users pay nothing for download or game play, and only some of them pay whenever they are willing to do for upgrade their character or level up (The New York Times 2014). The in-app purchase revenue, paying after free download, is the key of success in freemium business model. For this reason, mobile app marketers are interested in the way of enhancing the in-app purchase sales. While a series of study investigates the impact of in-app purchase option on the app's ranking (e.g., Jung et al. 2012; Lee and Raghu 2014), there exists little documentation about the determinants of in-app purchase sales amount.

In the mobile application industry, the ranking of mobile application affects consumer's demand (Carare 2012). Mobile application ranking is mainly broken down into two types, sales ranking and popularity rank, based on the amount of revenue and download, respectively. While the extant literature has continuously studied sales ranking of mobile application, comparatively little attention has been paid to popularity rank. Popularity rank is increasingly accentuated with the advent of freemium business model, due to the highlight on initial scaling up total user base. While there exist streams of academic endeavors to study search engine ranking (e.g., Agarwal et al. 2011; Animesh et al. 2011; Ghose and Yang 2009; Ghose et al. 2014; Feng et al. 2007) and sales rank (e.g., Brynjolfsson et al. 2003; Chevalier and Goolsbee 2003; Garg and Telang 2013), there exists little academic documentation about the popularity rank.

Considering the unprecedented pervasiveness of freemium business model, our endeavor to shed light on in-app purchase revenue and popularity rank is a timely guidance to the marketers' insight. For marketing practitioners, the deeper knowledge about how the mobile ad and popularity rank affect their revenue would help more optimal marketing decisions. In this context, this study aims to elucidate the relationship among mobile advertising, popularity rank, and in-app purchase revenue. For this purpose, we develop and test a series of hypotheses by constructing an empirical model. Our hypotheses are as follows. (1) Mobile advertising positively relates to popularity rank. (2) Popularity rank is associated positively with in-app purchase. (3) Popularity rank mediates the effect of mobile advertising on in-app purchase sales. In order to examine these hypotheses, we perform conventional 3-step mediated regression approach and Bayesian mediation approach.

The remainder of this article is organized as follows: We first review the related literature and develop hypotheses. Next, we describe our data, specify models related to our hypotheses, and report empirical findings. Finally, we conclude with managerial implications and future research suggestions.

\section{THEORETICAL FRAMEWORK AND HYPOTHESES}

Our proposed conceptual framework is depicted in Figure 1. In this framework, we construct an empirical model consisting of mobile advertising, popularity rank, and in-app purchase sales. We expect mobile advertising activities affect in-app purchase sales, not only directly, but also indirectly by improving the popularity rank and subsequently enhancing in-app purchase sales. Therefore, our conceptual model depicts popularity rank mediating the impact of advertising on in-app purchase sales of mobile apps. 
Figure 1. Conceptual Framework

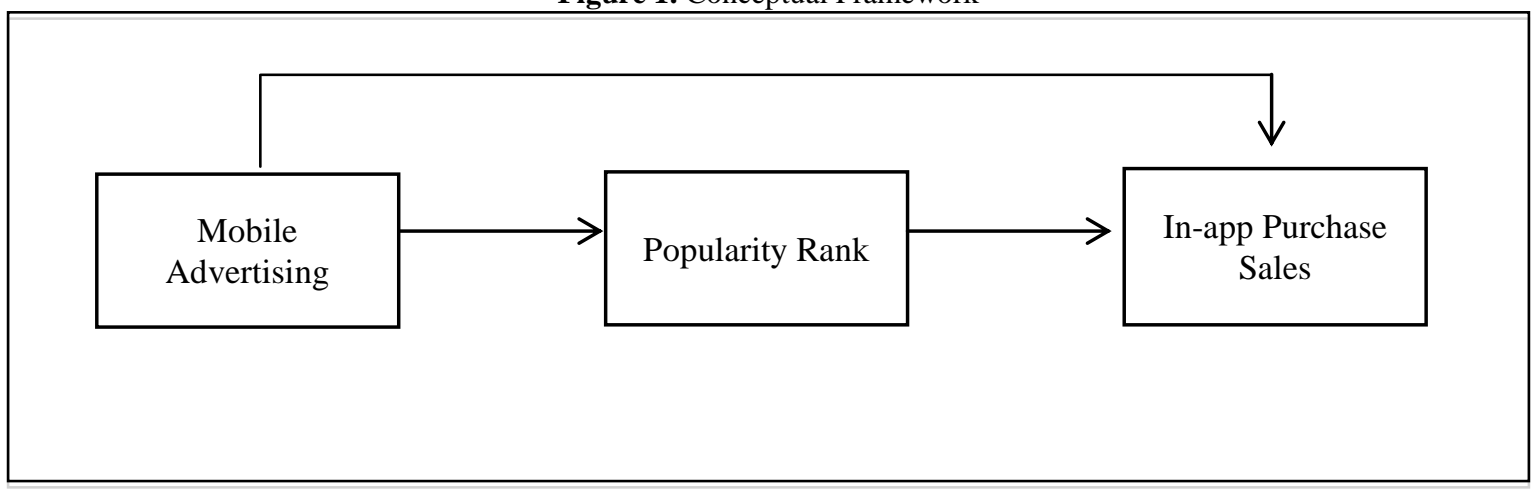

\subsection{Characteristics of Mobile Application Market}

As all of these concepts are closely related to mobile devices, we begin our theoretical discussions with characteristics of mobile devices compared to traditional personal computer (PC). While both mobile device and PC provide instant access to various information sources, Internet browsing activities through those two devices are somewhat different from each other. As for the user interface (UI), mobile devices generally provide quite smaller input devices and screens than those of PCs (Mahmoud and Yu 2006). In addition, the ranking effects on clicks are higher on the mobile interface, which suggests that the smaller screen size of mobile device increases the cost of browsing (Ghose et al. 2012). Actually, finding a new mobile application is not an easy task, because users should know what to look for or surf endless lists of apps (Girardello and Michahelles 2010). Considering relatively burdensome search for mobile apps, the mobile app rank is a good informative source for mobile users, which reduces their consideration sets in an effective way.

In addition to the different characteristics of mobile browsing activities, mobile app market also shows distinct properties compared to the traditional digital product markets. With regard to the market property, Zhong and Michahelles (2013) insist that mobile app market provided by Google Play (formerly Android market) is a "Superstar" market where a few popular hit products strongly dominate, rather than a "Long tail market" where a number of unpopular niche products constitute a substantial market share. According to Lee and Raghu (2014), mobile app market allows fewer access channels for consumers to mobile apps (e.g., just a single channel in Apple's App Store), compared to other digital product markets of book, music, and DVDs. Thus, mobile app market is different from the previous digital product markets in that it is dominated by fewer superstar products and allows fewer access channels.

Consequently, referring to the mobile app ranking is an efficient way for consumers to lessen their burdens of searching in a limited access channel for mobile apps. Therefore, we can reasonably infer that the demand of consumers is also highly affected by the mobile app rank. The research of Carare (2012) provides a good empirical support for existence of the mobile app ranking effects on the consumers' demand, which shows consumers' greater willingness to pay (WTP) for a top ranked app than for the same unranked app, and the steep decrease of the WTP with lower ranked apps. While consumers' demand is highly affected by the mobile app rank, it also affects the marketing strategy of the mobile app seller. In the market condition where consumers' demand are highly driven by mobile app ranking, a key question for the mobile app marketers to maximize sales revenue is how to make their apps to join the "superstar" club, with a strategic management of the ranking of their apps in the access channel.

\subsection{Topics on the Rankings}

To extend our theoretical discussion to the role of mobile app ranking, we look into the extant literatures related to the rankings. A stream of research focused on elucidating significant impacts of rank order on clickthrough rates (CTR) and conversion rates (CR) in search advertising. The topics in this stream include CTR for an advertisement in search engine listing rank (Agarwal et al. 2011, Feng et al. 2007), CTR and CR in search engine keyword rank (Ghose and Yang 2009), CTR with a firm's rank in a sponsored search listing (Animesh et al. 2011), 
and search engine revenue with search engine rankings (Animesh et al. 2011). Another research stream is about calibrating sales quantity from sales rank data, to overcome the lack of precise sales quantity data. For example, a stream of literature investigates the relationship between sales rank and sales quantity in online book sellers (Brynjolfsson et al. 2003; Chevalier and Goolsbee 2003; Ghose et al. 2006). In addition, Carare (2012) and Garg and Telang (2013) calibrate consumer demand using sales rank in mobile app markets.

Although there has been the streams of research on search engine ranking (e.g., Feng et al. 2007; Ghose et al. 2014) and sales ranking (e.g., Chevalier and Goolsbee 2003; Garg and Telang 2013), there exists little academic researches on the popularity rank. The impact of initial popularity rank on survival duration of the products has been documented for music industry (Bhattachargee et al. 2007; Strobl and Tucker 2000), but the market environment is quite different from that of current mobile app market. As for the mobile app market, Lee and Raghu (2014) find that high initial popularity rank has positive impacts on the survival duration of mobile app in top chart. Although the study of Lee and Raghu (2014) is meaningful for the relationship between the popularity rank and success of mobile app, their model does not reflect the dynamics of popularity rank. In order to consider decaying characteristics of popularity rank, we adopt the dynamic ranking by allowing carryover effect in the model.

\subsection{The Effect of Mobile Advertising on the Popularity Rank}

Mobile advertising is growing fast as more and more consumers spend their time with mobile devices instead of traditional media. Although majority of prior studies have documented on the effectiveness of advertising expenditures (Chauvin and Hirschey 1993; Joshi and Hanssens 2010; Kim and Joo 2013; Luo and Donthu 2012), there is little academic research on mobile advertising (Shankar et al. 2010). In recent study on mobile marketing, Luo et al. (2013) demonstrate that sending mobile messages on the date of promotional events increases the purchase probability more than sending these messages two days before the event. Considering the purpose of mobile advertising for new application as recruiting new users through enriched messages, we can reasonably expect that the company's high level of advertising expenditure through mobile media may lead to increasing number of downloads, thereby boosting popularity rank on the same date.

Considering the above-mentioned theoretical backgrounds of mobile app popularity rank and advertising effects, we hypothesize the possible relationship between advertising and mobile app popularity rank such as follow:

Hypothesis 1. Mobile advertising positively relates to popularity rank.

\subsection{The Effect of Popularity Rank on In-App Purchase Sales}

According to Anderson (2009), the in-app purchase revenue model has been successful for PC game industry. While not yet dominant in all the software industries, the in-app purchase is one of the established revenue models for game providers. According to Lee and Raghu (2014), approximately 35\% of mobile apps in the App Store are free apps, and around $80 \%$ of these free apps include in-app purchase option. While Jung et al. (2012) demonstrate the lower survival rate of mobile apps with in-app purchase option in App Store top grossing chart, Ghose and Han (2014) show that the app demand increases with in-app purchase option in mobile app market. In spite of a series of study about the impact of in-app purchase "option", the extant research has not yet quantified the impact of in-app purchase sales "amount".

Among the competing mobile apps including in-app purchase options, the knowledge about the relationship between the popularity ranking and the in-app purchase sales amount is important to make optimal marketing decision. The positive association between popularity rank and in-app purchase sales is suggested by Garg and Telang (2013) who estimate the influence of in-app purchase option on number of downloads inferred by mobile app ranking. As a further step, we want to hypothesize the direct relationship between popularity ranking and the in-app purchase revenues.

Hypothesis 2. Popularity rank is associated positively with in-app purchase sales. 


\subsection{The Mediating Role of Popularity Rank}

Our next hypothesis explores whether the popularity rank mediates the impacts of mobile advertising on the in-app purchase sales. Bart et al. (2014) show that mobile advertising campaigns effectively increase consumer's favorable attitudes toward products and purchase intentions. Based on theories of information processing and persuasion (e.g., Arkes et al. 1991; Arkes et al. 1989; Hawkins and Hoch 1992; Hawkins et al. 2001), Bart et al. (2014) argue that mobile advertising work effectively by triggering consumer's recall. Considering above mentioned two proposed effects - the positive effect of advertising expenditure on popularity rank in H1, and the positive effect of popularity rank on the in-app purchase sales in $\mathrm{H} 2-$, a logical expectation is that popularity rank serves as the underlying mediator through which mobile advertising ultimately affects in-app purchase sales. Thus, we expect the mediating role of popularity ranking on the in-app purchase sales effects of mobile advertising.

Hypothesis 3. Popularity rank mediates the effect of mobile advertising on in-app purchase sales.

\section{EMPIRICAL ANALYSES}

In this section, we describe the data and model specifications. We then discuss the empirical results and implications.

\subsection{Data}

The mobile game is the most popular mobile app category representing about $20 \%$ of active applications followed by education and business in App Store. ${ }^{2}$ It adequately demonstrates general characteristics of mobile app market. According to App Annie and IDC (2014), South Korea benefits from leading edge mobile technology and service environment, and mobile app revenue of South Korea ranked the $3^{\text {rd }}$ in the global mobile app market following US and Japan. The empirical application in this article uses data from a mobile game publisher in South Korea during the 2-month launch period of a game in 2014. The main distribution channel of the game is Google Play $^{3}$. The data includes daily advertising expenditure, Google Play popularity rank, and in-app purchase sales. During the launch period, 323,565 users had newly registered and played the game. Starting from 21,927, the number of daily new registered users of the game decreases to 5,868 two months after the launch.

\subsection{Measures}

\subsubsection{Mobile Advertising}

Mobile marketing involves multi-way communication and promotion of a product between firm and customers using the mobile devices, and is becoming more important in retailing environment (Shanker et al. 2010). Game publishers utilize advertising through various channels, in order to induce new users to install and play their game apps. Once a gamer starts to play the game app, the user would be exposed to various in-app promotions while playing the game.

Typical mobile app advertising is categorized into display ads and rewarded ads. Display ads, having banners and pop-ups, are ad units highly visible within game portal sites and other mobile apps. Rewarded ads cover the payments for the users who install those promoted mobile apps through reward-based advertising apps. Those reward-based apps allow users to accumulate reward points that can be redeemed at offline stores such as fast food restaurants, coffee shops, and convenience stores. Such incentivized advertising is growing fast in the mobile ad market in South Korea. To game users, it provides cash rewards in return for installations. At the same time, it can effectively help the publishers to rank their new games on the top chart in the Google Play.

\footnotetext{
${ }^{2}$ Application Category Distribution, PocketGamer.biz (Accessed at Jan, 15 2015) [http://www.pocketgamer.biz/metrics/app-store/categories/]

${ }^{3}$ The Google Play for Android and the Apple App Store for iOS are the two largest distribution channels for mobile apps worldwide. However, Android devices take $90 \%$ share of the smartphone market in South Korea.
} 


\subsubsection{Popularity Rank}

Google Play ranking system is similar to that of the music chart (Bhattacharjee et al. 2007). It reflects the popularity of the game, mainly based on the number of app downloads. Top-ranked apps in the given category are exposed to users frequently, and thereby can have a high chance to be downloaded. Carare (2012) shows that consumer is willing to pay $\$ 4.5$ greater for a top ranked app than for the same unranked app. Goole Play provides mainly three types of charts within each category: Top Free, Top Paid, and Top Grossing. When a mobile game ranks within the Top 500 chart and gains visibility, it can create a great deal of downloads. Such snowball effect can help the game remain in the top chart for a while. However, when the game ranks out of the $500^{\text {th }}$, the ranking information is not publicly available. Our data includes the popularity ranking information of Top Free chart within game category up to ranking $500^{\text {th }}$.

\subsubsection{In-app Purchase Sales}

Google's Android platforms allow for in-app purchases of content, services, or subscriptions, thereby enabling app developers to earn additional revenue from paid or free apps (Garg and Telang 2013). Ghose and Han (2014) find that app demand could increase with the in-app purchase option. In our data, the publisher earns revenue from in-app purchases for items in the game, not from installation or subscription fee of the app. During the first month after launch, we can frequently observe, daily advertising expense exceeding daily revenue, as a strategic marketing decision of scaling up total user base in the initial stage. With such decision, publisher expects a positive return on investment from engaged users during the operating period of the game.

Table 1 shows the descriptive statistics of our data. In addition, Figure 2 presents the time series of advertising expenditure, in-app purchase revenue, and Google Play popularity rank in the top newly-introduced free game category.

Table 1. Descriptive Statistics

\begin{tabular}{lcrrr}
\hline \multicolumn{1}{c}{ Series } & Mean & SD & Min & Max \\
\hline In-app Purchase Sales & 1,443 & 975 & 204 & 4,144 \\
Popularity Rank & 102 & 97 & 6 & 500 \\
Mobile Advertising & 2,011 & 3,241 & 0 & 13,317 \\
\hline
\end{tabular}

* Sales and advertising is measured in USD.

Figure 2. Advertising, In-app Purchase Sales, and Popularity Rank

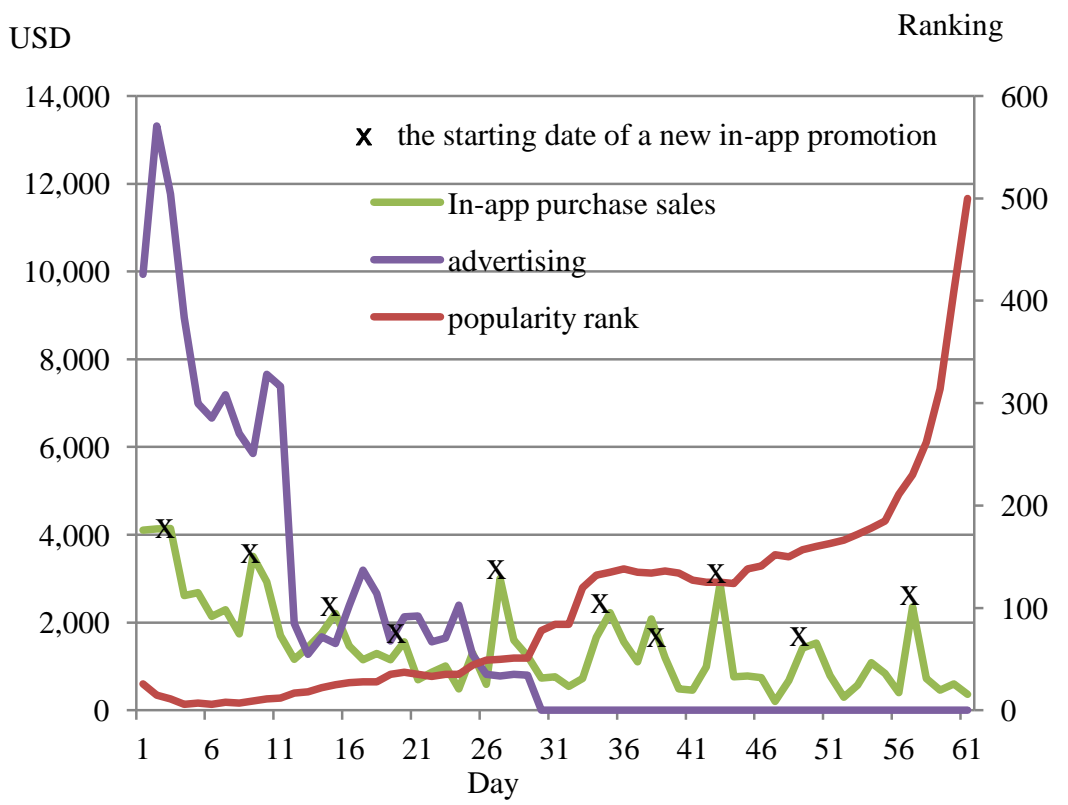




\subsection{Estimation Approach}

In our model, in-app purchase sales fluctuates depending on advertising spending and carryover effect (decaying over time). Therefore, we adopt the well-known Nerlove and Arrow (1962) model which allows us to capture the aggregate dynamic marketing response in parsimonious way. The dynamic changes in sales with respect to advertising is defined as follows:

$$
\frac{d S_{t}}{d t}=\beta^{A} A_{t}-\tilde{\rho}^{S} S_{t-1}
$$

where $\mathrm{S}$ is the sales of the product, $\tilde{\rho}^{S}$ is the rate of decays in sales, $\mathrm{A}$ is advertising expenditure, and $\beta^{A}$ is the effectiveness of advertising on sales.

For tractability, we assume discrete time $\left(\Delta \mathrm{S}_{\mathrm{t}}=\mathrm{S}_{\mathrm{t}}-\mathrm{S}_{\mathrm{t}-1}\right)$ following Rutz and Bucklin 2011. Then, this model can be rewritten as follows:

$$
S_{t}=\beta^{A} A_{t}+\rho^{S} S_{t-1}
$$

where $\rho^{S}=\left(1-\tilde{\rho}^{S}\right)$ is the carryover rate of sales (Naik et al. 1998). This model implies that goodwill accumulates as advertising expenditure increases, and decay exponentially when advertising is disabled. Extending Nerlove and Arrow model, we specify the dynamics for how advertising activity affects in-app purchase sales (or popularity rank) and capture the decaying characteristic of them.

To empirically test the mobile advertising effectiveness and the mediation role of popularity rank, we employ the 3-step approach suggested by Baron and Kenny (1986). The 3-step model considering carryover effects is written as follows:

$$
\begin{aligned}
& \text { Step1: } \text { Sales }_{\mathrm{t}}=\alpha^{1}+\beta^{1} \mathrm{Ad}_{\mathrm{t}}+\gamma^{1} \text { Promo }_{\mathrm{t}}+\rho^{1} \operatorname{Sales}_{\mathrm{t}-1}+\varepsilon_{\mathrm{t}}^{1} \\
& \text { Step2: } \operatorname{Rank}_{\mathrm{t}}=\alpha^{2}+\beta^{2} \mathrm{Ad}_{\mathrm{t}}+\gamma^{2} \text { Promo }_{\mathrm{t}}+\rho^{2} \operatorname{Rank}_{\mathrm{t}-1}+\varepsilon_{\mathrm{t}}^{2} \\
& \text { Step3: } \text { Sales }_{\mathrm{t}}=\alpha^{3}+\varphi^{3} \operatorname{Rank}_{\mathrm{t}}+\beta^{3} \mathrm{Ad}_{\mathrm{t}}+\gamma^{3} \text { Promo }_{\mathrm{t}}+\rho^{3} \text { Sales }_{\mathrm{t}-1}+\varepsilon_{\mathrm{t}}^{3}
\end{aligned}
$$

where $\rho:$ the rate of decay, Sales $: \log$ of in-app purchase sales, Ad $: \log$ of mobile advertising expenditures, Promo : if a new promotional event is held by the publisher in the game, then 1 (otherwise 0), Rank : log of popularity rank, and $\varepsilon$ is error term. In our model specification, we take logarithms of sales, ranks, and advertising variables to reduce the effect of skewness.

In classic mediation approach (Lee et al. 2011; Luo and Donthu 2006), mediating variable (Rank) lies in the causal sequence between the independent variable $(A d)$ and dependent variable (Sales). At the first step, as the baseline model, in-app purchase sales is regressed on advertising. To test its mediating effect, rank is regressed against advertising in the second step. At the final step, we measure the channel effect of rank in the relationship between advertising and sales. That is, the publisher's advertising spending directly improves rank, which in turn leads to increase in the publisher's sales. Therefore, sales is regressed on rank.

In the stylized mediation model, the direct effect of advertising on firm value without considering the mediator is measured by $\beta^{1}$. To assess the mediating effect of rank, we estimate the effect of advertising on sales, after the mediating variable (Rank) is included in the equation (5). If the effect of advertising on sales disappears (or diminishes) in terms of significance of the $\beta^{3}$, estimate the popularity rank fully (or partially) mediate the advertising effect on the in-app purchase sales as suggested by H3. Mediation by rank is complete if $\beta^{1}, \varphi^{3} \cdot \beta^{2}$ are significant but $\beta^{3}$ is not, and it is partial if all of them are significant. However, the indirect effect of advertising on sales through popularity rank $\left(\varphi^{3} \cdot \beta^{2}\right)$ is not testable in the classic mediation model, because the product of two normally distributed coefficients is not normally distributed. 
To accurately test the mediation hypothesis (H3), we adopt a Bayesian-based mediation approach (Zhang et al. 2009). Using Markov Chain Monte Carlo (MCMC) estimation process, it allows for computing standard errors of a mediated effect $\left(\varphi^{3} \cdot \beta^{2}\right)$ from an empirical sampling distribution. In addition, the Bayesian approach allows us to account for possible biases due to omitted variables and measurement error. For example, common unobserved factors (e.g., interests for the app) may influence both rank and in-app purchase sales. Then an endogeneity problem may occur as a result of possible spurious relationship between popularity rank and sales. In an effort to overcome this problem, we utilize Bayesian mediation analysis, taking various sources of endogeneity into account (Luo et al. 2012; Oh 2013).

\subsection{Empirical Results}

In this section, we first provide the hypothesis testing results from the classic mediation analysis as a baseline model. Then the results from Bayesian mediation analysis are discussed to confirm the mediating role of popularity rank. Table 2 shows our empirical results from the conventional 3-step mediated regression approach (Baron and Kenny 1986). In Model 1 , advertising significantly improves popularity rank (=-0.037, p $<0.05)$. Therefore $\mathrm{H} 1$ is supported. This suggests that, all else being equal, higher advertising expenditure helps a mobile game to rank higher in the popularity chart. That is, $10 \%$ increase in advertising can boost the ranking by $0.15 \%{ }^{4}$. Without rank variable (Model 2), advertising has significant and positive effects on sales $(=0.059, \mathrm{p}<0.05, \mathrm{H} 2$ is supported). After inclusion of rank variable (Model 3), the advertising effect on sales disappears while the rank effect on sales is still significant and negative, supporting a complete mediation. That is, popularity rank completely accounts for the positive effect of advertising on sales (H3 is supported).

In addition to advertising, promotional event explains the daily in-app purchase sales significantly, whereas it has an insignificant effect on popularity rank. These practices include: free game item giveaways, game item discount, level-up event, and updating the game maps. Those promotional tools play a key role to create excitements to the game users, enticing them to purchase game items in the app. Usually a new event generates a dramatic increase in the in-app purchase sales on the first day and it continues 6-14 days depending on users' responses. Due to the cost effectiveness, after certain periods have passed, the game publisher phases out advertising and focuses on in-app purchase promotions to retain current users.

Decaying coefficients for popularity rank and in-app purchase sales turns out to be 0.893 (Model 1) and 0.315 (Model 3), respectively ( $\mathrm{p}<0.05$ ). It suggests that popularity rank on the previous day has a significant influence on the next day's ranking even after control for advertising effect. In-app purchase sales also has some carryover effect, but its extent is smaller than that of popularity rank. Popularity rank (or advertising) and in-app promotion turns out to be important determinants of in-app purchase sales beyond the carryover effect.

${ }^{4}$ All else being equal, $\log \left(\operatorname{Rank1/Rank2)}=\widehat{\beta^{2}} \log (\operatorname{Ad} 1 / \mathrm{Ad} 2)\right.$. 
Table 2. Classic Mediation Test Results

\begin{tabular}{|c|c|c|c|}
\hline \multirow[t]{3}{*}{ Independent Variable } & \multicolumn{3}{|c|}{ Dependent Variable } \\
\hline & \multirow{2}{*}{$\begin{array}{c}\text { Popularity Rank } \\
\text { Model } 1 \\
\end{array}$} & \multicolumn{2}{|c|}{ In-app Purchase Sales } \\
\hline & & Model 2 & Model 3 \\
\hline Popularity Rank & & & $\begin{array}{l}-0.268^{*} \\
(0.141)\end{array}$ \\
\hline Mobile Advertising & $\begin{array}{l}-0.037 * * \\
(0.013)\end{array}$ & $\begin{array}{l}0.059 * * \\
(0.010)\end{array}$ & $\begin{array}{c}-0.004 \\
0.039)\end{array}$ \\
\hline In-app Promotion & $\begin{array}{c}0.020 \\
(0.091)\end{array}$ & $0.492 * *(0.002)$ & $\begin{array}{l}0.537 * * \\
(0.184)\end{array}$ \\
\hline Popularity Rank (t-1) & $\begin{array}{l}0.893 * * \\
(0.045)\end{array}$ & & \\
\hline In-app Purchase Sales (t-1) & & $\begin{array}{l}0.351 * * \\
(0.111)\end{array}$ & $\begin{array}{l}0.315 * * \\
(0.110)\end{array}$ \\
\hline Intercept & $\begin{array}{c}0.617 * \\
(0.234)\end{array}$ & $\begin{array}{l}4.267 * * \\
(0.750)\end{array}$ & $\begin{array}{l}5.862^{* * *} \\
(1.116)\end{array}$ \\
\hline$F$-value & $902.38 * *$ & $18.07 * *$ & $15.06 * *$ \\
\hline & 0.979 & 0.483 & 0.514 \\
\hline Adjusted $R^{2}$ & 0.978 & 0.456 & 0.480 \\
\hline
\end{tabular}

Notes: All variables are logged to reduce skewness. Standard errors are in parentheses.

$*=\mathrm{p}<0.10 ; * *=\mathrm{p}<0.05$ (two-tailed test).

Although standard mediation technique is widely used to investigate mediators, it cannot measure standard errors of mediated effect. Thus, we fit the model using Bayesian MCMC methods with Gibbs sampling to accurately test the significance of mediating effect (Zhang et al. 2009). In Table 3, the mediated effect (i.e. indirect effect) of mobile advertising on in-app purchase sales equals to 0.010 and significant $(\mathrm{p}<0.05)$. It suggests that popularity rank completely mediates the influence of advertising on in-app purchase sales.

Table 3. Bayesian Mediation Results

\begin{tabular}{|c|c|c|}
\hline \multirow[t]{2}{*}{ Independent Variable } & \multicolumn{2}{|c|}{ Dependent Variable } \\
\hline & Popularity Rank & In-app Purchase Sales \\
\hline Popularity Rank & & $\begin{array}{l}-0.276^{*} \\
(0.158)\end{array}$ \\
\hline Mobile Advertising & $\begin{array}{l}-0.037 * * \\
(0.013)\end{array}$ & $\begin{array}{l}-0.005 \\
(0.042)\end{array}$ \\
\hline In-app Promotion & $\begin{array}{c}0.021 \\
(0.064)\end{array}$ & $\begin{array}{l}0.525 * * \\
(0.199)\end{array}$ \\
\hline Popularity Rank (t-1) & $\begin{array}{l}0.892 * * \\
(0.047)\end{array}$ & \\
\hline In-app Purchase Sales (t-1) & & $\begin{array}{l}0.308 * * \\
(0.111)\end{array}$ \\
\hline Intercept & $\begin{array}{l}0.618 * * \\
(0.240)\end{array}$ & $\begin{array}{l}5.958 * * \\
(1.328)\end{array}$ \\
\hline$\sigma^{2}$ & $\begin{array}{l}0.518^{* *} \\
(0.049)\end{array}$ & $\begin{array}{l}0.169 * * \\
(0.016)\end{array}$ \\
\hline Mediated Effect of Advertising & $\begin{array}{c}0.010^{*} \\
(0.007)\end{array}$ & \\
\hline$D I C^{5}$ & -39.249 & 98.149 \\
\hline
\end{tabular}

\section{CONCLUSION}

The objective of this study is to investigate how popularity rank influences the effects of mobile advertising on in-app purchase sales performance in a new mobile app launching context. This paper contributes to the rapidly

${ }^{5}$ Deviance information criterion 
growing field of mobile marketing by highlighting the importance of popularity rank. Using a unique data set from a mobile game publishing company in South Korea, we are able to explain the relationship among key variables: mobile advertising, popularity rank, and in-app purchase sales.

We employ a recently developed methodology to test the mediation effects, Bayesian mediation approach, in addition to the classic 3-step mediation analysis. Our main empirical findings are as follows. First, we find that mobile advertising spending in mobile app company significantly improves popularity rank. Second, the improved popularity rank enhances the game users' in-app purchase sales. Third, advertising effect on the firm's revenue is completely mediated by popularity ranking on the top chart. To the best of our knowledge, this study is the first study to demonstrate mediation role of popularity ranking.

This study provides helpful managerial insights for mobile app developers, publishers and distributors on the role of mobile marketing and popularity rank. Under the freemium business model, popularity rank plays an important role to increase seller's revenue from in-app purchase by enlarging total user base. Consequently, at the launching stage of a new mobile app, managers need to strategically allocate their advertising budget to rank up the app in the top-chart of the category and thereby maximize sales revenue. In addition, our results suggest that mobile advertising contributes in-app purchase sales through improving popularity rank (complete mediation), while in-app promotion directly boosts in-app purchase sales. Thus, managers should strategically mix these two promotional tools depending on the mobile app launching stages. For example, to maximize profits from in-app purchase, managers might emphasize the role of advertising at the initial period, with monitoring popularity rank as a mediator. Once a sufficiently large base of users is acquired, managers might start to increase budgets for in-app promotional activities while phasing out advertising. In sum, as the popularity rank turns out to be a valid mediator for the sales effects of mobile advertising, the strategic management of popularity rank through advertising would be useful for predicting sales revenue and profits generating from the app.

Our analyses have some limitations, with related suggestions for future research. First, although daily ranking information is publicly available, daily-level advertising spending and sales information of an individual mobile game are not easily accessible. If we can obtain data for other mobile game apps, we can cross-validate the mediating role of ranking in the relationship between mobile advertising and in-app purchase sales. Second, our data is limited to just one category, mobile game. We can also test how much the mediating effect of popularity rank varies across categories as a possible extension of this study. Third, our data includes only aggregated advertising spending information. If researchers can access daily disaggregated advertising spending information (i.e., display ad, social network service (SNS), reward-type ad, etc.), an analytical approach to optimal advertising budget allocation would be also a possible direction of future developments. We hope future research in mobile marketing will benefit from more enhanced data to address these limitations.

\section{ACKNOWLEDGEMENTS}

The authors have benefitted from valuable insights and comments of Jonghyung Park.

\section{AUTHOR INFORMATION}

Yun Kyung Oh is an assistant professor at Department of Business Administration of Dongduk Women's University, South Korea. She received her Ph.D. at Purdue University. Her research interests include digital marketing, online retailing and financial value of marketing investment. E-mail: ykoh1@ dongduk.ac.kr

Jihong Min is an assistant professor at College of Business Administration of Myongii University, South Korea. He earned his Ph.D. at Purdue University. His research areas include structural consumer model, database marketing, and marketing-finance interface. E-mail: jhmin @ mju.ac.kr (Corresponding author)

\section{REFERENCES}

Agarwal, A., Hosanagar, K., \& Smith, M. D. (2011). Location, location, location: An analysis of profitability of position in online advertising markets. Journal of Marketing Research, 48 (6), 1057-1073. 
Anderson, C. (2009). Free. Hyperion. New York.

Animesh, A., Viswanathan, S., \& Agarwal, R. (2011). Competing "creatively" in sponsored search markets: The effect of rank, differentiation strategy, and competition on performance. Information Systems Research, 22 (1), 153-169.

App Annie \& IDC (2014) Mobile App Advertising and Monetization Trends 2012-2017: The Economics of Free, Mar, 24. Accessed at Jan. 15, 2015. [Available at http://blog.appannie.com/app-annie-idc-mobile-appadvertising-and-monetization-trends-2012-2017]

Arkes, H. R., Boehm, L. E., \& Xu, G. (1991). Determinants of judged validity. Journal of Experimental Social Psychology, 27(6), 576-605.

Arkes, H. R., Hackett, C., \& Boehm, L. (1989). The generality of the relation between familiarity and judged validity. Journal of Behavioral Decision Making, 2 (2), 81-94.

Baron, R. M. \& Kenny, D. A. (1986), "The Moderator-Mediator Variable Distinction in Social Psychological Research: Conceptual, Strategic, and Statistical Considerations," Journal of Personality and Social Psychology, 51 (6), 1173-82.

Bart, Y., Stephen, A. T., \& Sarvary, M. (2014). Which products are best suited to mobile advertising? A field study of mobile display advertising effects on consumer attitudes and intentions. Journal of Marketing Research, 51(3), 270-285.

Bhattacharjee, S., Gopal, R. D., Lertwachara, K., Marsden, J. R., \& Telang, R. (2007). The effect of digital sharing technologies on music markets: A survival analysis of albums on ranking charts. Management Science, 53 (9), 1359-1374.

Brynjolfsson E, Hu Y, \& Smith, M. D. (2003) Consumer surplus in the digital economy: Estimating the value of increased product variety at online booksellers. Management Science, 49 (11), 1580-1596.

Carare, O. (2012). The impact of bestseller rank on demand: evidence from the app market. International Economic Review, 53 (3), 717-742.

Chauvin, K. W. \& Hirschey, M. (1993). Advertising, R\&D Expenditures, and the Market Value of the Firm. Financial Management, 22 (Winter), 128-140.

Chevalier, J. \& Goolsbee, A. (2003) Measuring prices and price competition online: Amazon.com and BarnesandNoble.com. Quantitative Marketing Economics 1 (2), 203-222.

Feng, J., Bhargava, H. K., \& Pennock, D. M. (2007). Implementing sponsored search in web search engines: Computational evaluation of alternative mechanisms. INFORMS Journal on Computing, 19 (1), 137-148.

Fields, T. (2014). Mobile \& Social Game Design: Monetization Methods and Mechanics. CRC Press.

Garg, R. \& Telang, R. (2013). Inferring app demand from publicly available data. MIS Quarterly, 37 (4), 1253 1264.

Ghose, A., Goldfarb, A., \& Han, S. P. (2012). How is the mobile Internet different? Search costs and local activities. Information Systems Research, 24 (3), 613-631.

Ghose, A. \& Han, S. P. (2014). Estimating Demand for Mobile Applications in the New Economy. Management Science, 60(6):1470-1488. http://dx.doi.org/10.1287/mnsc.2014.1945

Ghose, A., Ipeirotis, P. G., \& Li, B. (2014). Examining the Impact of Ranking on Consumer Behavior and Search Engine Revenue. Management Science, 60(7):1632-1654. http://dx.doi.org/10.1287/mnsc.2013.1828

Ghose, A., Smith M. D., \& Telang, R. (2006). Internet exchanges for used books: An empirical analysis of product cannibalization and welfare impact. Information Systems Research, 17 (1), 3-19.

Ghose, A. \& Yang, S. (2009). An empirical analysis of search engine advertising: Sponsored search in electronic markets. Management Science, 55(10), 1605-1622.

Girardello, A. \& Michahelles, F. (2010, September). AppAware: Which mobile applications are hot?. In Proceedings of the 12th international conference on Human computer interaction with mobile devices and services (pp. 431-434). ACM.

Hawkins, S. A. \& Hoch, S. J. (1992). Low-involvement learning: Memory without evaluation. Journal of Consumer Research, 212-225.

Hawkins, S. A., Hoch, S. J., \& Meyers-Levy, J. (2001). Low-involvement learning: Repetition and coherence in familiarity and belief. Journal of Consumer Psychology, 11(1), 1-11.

Joshi, A. \& Hanssens, D. (2010). The direct and indirect effects of advertising spending on firm value. Journal of Marketing, 74(1), 20-33.

Jung, E. Y., Baek, C., \& Lee, J. D. (2012). Product survival analysis for the App Store. Marketing Letters, 23 (4), 929-941. 
Kim, Y. \& Joo, J. (2013). The Moderating Effect Of Product Market Competition In The Relationship Between Advertising Expenditures And Sales. Journal of Applied Business Research, 29(4), 1061-1076.

Kumar, V. (2014). Making" freemium" work. Harvard business review, 92 (5), 27-29.

Lee, G. \& Raghu, T. S. (2014). Determinants of Mobile Apps' Success: Evidence from the App Store Market. Journal of Management Information Systems, 31 (2), 133-170.

Lee, R. P., Naylor, G., \& Chen, Q. (2011). Linking customer resources to firm success: The role of marketing program implementation. Journal of Business Research, 64 (4), 394-400.

Luo, X., Andrews, M., Fang, Z., \& Phang, C. W. (2013). Mobile targeting. Management Science. (published electronically December 20), [DOI: 10.1287. mnsc. 2013.1836].

Luo, X. \& Donthu, N. (2006). Marketing's credibility: a longitudinal investigation of marketing communication productivity and shareholder value. Journal of Marketing, 70 (4), 70-91.

Luo, X., Wieseke, J., \& Homburg, C. (2012). Incentivizing CEOs to build customer-and employee-firm relations for higher customer satisfaction and firm value. Journal of the Academy of Marketing Science, 40 (6), $745-758$.

Mahmoud, Q. H. \& Yu, L. (2006). Havana agents for comparison shopping and location-aware advertising in wireless mobile environments. Electronic Commerce Research and Applications, 5 (3), 220-228.

Moreira, Á. V., Vicente Filho, V., Barros, G. A., de Carvalho, L. V., \& Albuquerque, G. L. R. (2013) Which features matter to make a successful mobile game?. SBC-Proceedings of SBGames 2013

Naik, P. A., Mantrala, M. K., \& Sawyer, A. G. (1998). Planning media schedules in the presence of dynamic advertising quality. Marketing Science, 17 (3), 214-235.

Nakamura, Y \& Huang, G. (2014). "Google Turns to 'Monster Strike' to Close Apple App Gap" Businessweek, September 12, (Accessed at Jan 15, 2015) [available at http://www.businessweek.com/news/2014-0911/google-turns-to-monster-strike-to-close-apple-app-gap]

Nerlove, M. \& Arrow, K. J. (1962). Optimal advertising policy under dynamic conditions. Economica, 129-142.

Nick, W. (2014) Free video games say pay up or wait, testing players' patience. The New York Times, Jul 5, (Accessed at Jan 15, 2015), [Accessed at http://www.nytimes.com/2014/07/06/technology/free-videogames-say-pay-up-or-wait-testing-players-patience.html?_r=0]

Oh, Y. K. (2013), Informative role of marketing activity in financial market: evidence from analysts' forecast dispersion, Asia Marketing Journal, 15 (3), 53-77.

Rutz, O. J. \& Bucklin, R. E. (2011). From generic to branded: A model of spillover in paid search advertising. Journal of Marketing Research, 48 (1), 87-102.

Shankar, V., Venkatesh, A., Hofacker, C., \& Naik, P. (2010). Mobile marketing in the retailing environment: current insights and future research avenues. Journal of Interactive Marketing, 24 (2), 111-120.

Strobl, E. A. \& Tucker, C. (2000) The dynamics of chart success in the U.K. pre-recorded popular music industry. Journal of Cultural Economics, 24, 2, 113-134.

Zhang, J., Wedel, M., \& Pieters, R. (2009), Sales Effects of Attention to Feature Advertisements: A Bayesian Mediation Analysis, Journal of Marketing Research, 46 (5), 669-81.

Zhong, N. \& Michahelles, F. (2013). Google Play is not a long tail market: an empirical analysis of app adoption on the Google Play app market. 68 In Proceedings of the 28th Annual ACM Symposium on Applied Computing, ACM. 499-504.

Zinevych, S. (2014) The Overview of Mobile Apps Market: Why You Should Enter Now, B2C, Sep. 1, Accessed at Nov, 28, 2014. [Available at http://www.business2community.com/mobile-apps/overview-mobile-appsmarket-enter-now-0994728] 